\section{A link between maternal thyroid hormone and sexual orientation?}

\section{Jeffrey Mullen \\ University of California, Irvine, CA, USA}

The search for the cause of gender nonconformity and homosexuality has been extensive. Researchers have proposed a variety of different causes, from early childhood experiences to birth order to hormonal influences, ${ }^{1-3}$ but have yet to pinpoint a reliable explanation of our sexual orientation. Prior research into biological influences of sexual orientation has focused on adult hormone levels, ${ }^{3}$ and more recent studies have even considered both maternal and fetal prenatal hormone levels. ${ }^{4}$ However, no previous studies have associated maternal thyroid hormone levels with sexual orientation and gender identity. The study by Sabuncuoglu presents evidence to supporting the hypothesis that maternal thyroid hormone levels during pregnancy are associated with sexual orientation and gender identity. 5

Though social acceptance of homosexuality has greatly increased in recent years, Sabuncuoglu's article begins with a reminder that stigma still exists, ${ }^{5}$ and that the increased stressors faced by this population are likely to contribute to higher risk behavior resulting in negative health outcomes. It is therefore of importance to the medical community to fully understand the underlying cause of gender nonconformity in order to have options to prevent and treat the negative health outcomes referred to in this article. Additionally, this line of research may be of interest to parents, who, even if fully accepting of gender nonconformity, may prefer not to contribute to factors leading to their own child's homosexuality if those factors were known and preventable.

The author points out the significant role that thyroid hormones play during fetal development, including neurodevelopment and cell differentiation. Research has even associated maternal thyroid function with behavioral problems in childhood. 6 Pregnancy puts an increased demand on the thyroid, and it typically responds with increased hormone production. ${ }^{7}$ One mechanism that increases thyroid productivity is human chorionic gonadotropin, which stimulates thyroid production during early pregnancy. However, women with thyroid dysfunction are less able to accommodate the increased demand regardless of the mechanism of stimulation, leading to effects on the developing fetus. Despite the known importance of thyroid function on fetal development, prior research has not recognized its association with sexual orientation. Sabuncuoglu refers to the androgen model, which has failed to convincingly associate the level of fetal androgen exposure with homosexuality. Androgen's role as a sex hormone made it a logical focus of study, but the author all but rebukes this notion due to the lack of consistent results. This study instead focuses on the thyroid, as it is known to have such an important role in fetal psycho-neurological development and yet is so curiously understudied in this regard. It is interesting to note that that the rates of hypothyroidism and homosexuality are so similar, with both often accepted to be between three to five percent of the total population, which may hint at some form of correlation.

This study included patients who presented to the author-clinician, a child and adolescent psychiatrist. Participants were selected if their presentation was consistent with gender nonconformity or homosexuality, and their mothers were contacted and interviewed about their thyroid history. The mean age of the children who exhibited gender nonconformity was just over twelve years old. According to some, sexual orientation is fully formed long before this age, but other theories hold that this may be too young to have had the experiences that influence our sexual orientation. It should also be noted that sexual orientation exists on a continuum including those who are bisexual and those who are bisexual but identify as more strongly as either heterosexual or homosexual. Subsequent research may be able to identify more factors that lead to an individual's specific position along this spectrum.

Whether or not maternal thyroid dysfunction causes homosexuality, this study presents data that strongly suggest that there is an association between the two. Though past research has not been able to attribute a single factor to the development of sexual orientation, future research may find additional contributing factors. Ultimately, this study has made a very compelling point concerning the very nature of gender nonconformity and sexual orientation. Those findings will likely prove to be important to our understanding of the topic, and will serve as a point of reference from which future research will be directed.
Correspondence: Jeffrey Mullen,

University of California, Irvine, CA 92697, USA.

E-mail: jamullen@uci.edu

Key words: Gender nonconformity; homosexuality; maternal thyroid; sexual orientation.

Conflict of interest: the author declares no potential conflict of interest.

Received for publication: 10 May 2016.

Accepted for publication: 10 May 2016

This work is licensed under a Creative Commons Attribution-NonCommercial 4.0 International License (CC BY-NC 4.0).

(C)Copyright J. Mullen, 2016

Licensee PAGEPress, Italy

Mental Illness 2016; 8:6591

doi:10.4081/mi.2016.6591

\section{References}

1. Schilder A, Anema A, Pai J, et al Association between childhood physical abuse, unprotected receptive anal intercourse and HIV infection among young men who have sex with men in Vancouver, Canada. PLOS One 2014;9:e100501.

2. Schwarz G, Kim R, Kolundzija A, et al. Biodemographic and physical correlates of sexual orientation in men. Arch Sex Behav 2010;39:93-109.

3. Corsello S, Donna V, Senes P, et al Biological aspects of gender disorders. Minerva Endocrinol 2011;36:325-39.

4. Balthazart J. Minireview: hormones and human sexual orientation. Endocrinology 2011;152:2937-47.

5. Sabuncuoglu 0. High rates of same-sex attraction/gender nonconformity in the offspring of mothers with thyroid dysfunction during pregnancy: proposal of prenatal thyroid model. Ment Illn 2015;7:5810.

6. Ghassabian A, Bongers-Schokking J, Henrichs J, et al. Maternal thyroid function during pregnancy and behavioral problems in the offspring: the generation R study. Pediatr Res 2011;69:454-9.

7. Lazarus J. Thyroid regulation and dysfunction in the pregnant patient. In: De Groot LJ, Beck-Peccoz P, Chrousos G, et al, eds. Endotext [Internet]. South Dartmouth (MA): MDText.com, Inc.; 2000. 